\title{
ТЕХНОЛОГИИ ИСКУССТВЕННОГО ИНТЕЛЛЕКТА В УПРАВЛЕНИИ ЧЕЛОВЕЧЕСКИМИ РЕСУРСАМИ
}

\author{
Е.В. Ванкевич, И.Н. Калиновская*
}

Разработаны методы использования технологий искусственного интеллекта в системе управления человеческими ресурсами организации на основе обработки и интерпретации больших данных. Обоснована концепция использования искусственного интеллекта для социального скоринга при найме потенциальных кандидатов на рабочие места, в соответствии с которой разработана архитектура программного продукта, позволяющего с помощью технологий кадрового профайлинга по информации из социальных сетей оценить степень готовности соискателя выполнять круг профессиональных обязанностей должности, на которую он претендует. Предложены рекомендации по применению направлений внедрения искусственного интеллекта.

Ключевые слова: управление человеческими ресурсами, подбор персонала, искусственный интеллект, социальный скоринг, кадровый профайлинг.

JEL-классификация: J24, M51.

DOI: $10.46782 / 1818-4510-2020-2-38-51$

Материал поступил 28.02.2020 2.

Повышение эффективности использования человеческих ресурсов в современных условиях является приоритетной задачей как для конкретного предприятия, так и для национальной экономики в целом. Для этого на всех уровнях национальной экономической системы необходимо внедрение современных технологий управления человеческими ресурсами ${ }^{1}$. В данном процессе оптимальным инструментом может выступать искусственный интеллект и программные продукты, созданные на его основе, поскольку в условиях цифровизации экономики они получают широкое распространение.

Яркими примерами использования искусственного интеллекта являются: автоматизированные системы производства; экспертные системы и базы данных; машинный перевод; технологии распознавания и идентификации объектов; сбор и анализ информации со спутников; использование спамфильтров электронной почты; систе-

1 Vankevich A. 2005. Personnel strategy and their realization at the Belarusian enterprises. Journal of Business Economics and Management. PP. 101-112. мы идентификации «пиратских» ботов; технология индивидуального предложения рекламы путем фильтрации поисковых запросов; создание «умных» часов, фитнесбраслетов и устройств в области медицинской диагностики; технология блокчейн и т. д. (Пантелеева, Арустамов, Максаев, 2019). Современное обилие информации, скорость ее обработки и разнообразие сведений уже не позволяют применять привычные программные или аппаратные средства. Большие данные накапливаются практически в любой сфере человеческой деятельности, требуя внедрения все более эффективных систем хранения и обработки информации. Все это создает предпосылки для применения технологий искусственного интеллекта в бизнес-практике. В этих условиях важной теоретической и прикладной задачей становится программирование технологий управления человеческими ресурсами для получения возможности быстрого и эффективного принятия решений при реализации отдельных кадровых процессов. С одной стороны, это создает воз-

* Ванкевич Елена Васильевна (vankevich_ev@tut.by), доктор экономических наук, профессор, Витебский государственный технологический университет (г. Витебск, Беларусь);

Калиновская Ирина Николаевна (i-kalinovskaya@yandex.by), кандидат технических наук, Витебский государственный технологический университет (г. Витебск, Беларусь). 
можность для обработки больших массивов разрозненной информации о потенциальном кандидате на рабочее место, более полно учесть всю имеющуюся информацию о кандидате (в социальных сетях, мессенджерах, поисковых системах, специальных базах данных). С другой стороны, использование таких технологий позволит специалистам по управлению человеческими ресурсами быстро и объективно принимать решения. В совокупности это снизит информационную асимметрию на рынке труда и повысит прозрачность принимаемых решений для всех участников (HR-специалистов, нанимателей, собственников предприятий, кандидатов на должность) (Ванкевич, Кастел-Бранко, 2017. С. 73-92).

\section{Возможности применения технологий искусственного интеллекта в практике управления человеческими ресурсами}

Рынок труда стремительно меняется: трансформируются его методы и стратегии, появляются новые подходы в поиске, под- боре, обучении, мотивации и оценке эффективности трудовых ресурсов. Действенным инструментом данных изменений выступает искусственный интеллект. Ни одна из областей кадровой политики в будущем не сможет обходиться без применения программных продуктов, разработанных на базе нейронных сетей. На рис. 1 приведены направления кадровой политики предприятия, в которых возможно использование искусственного интеллекта.

Согласно прогнозам американской исследовательской и консалтинговой компании «Grand View Research Inc.», глобальный сектор управления человеческими ресурсами (HRM) к 2025 г. достигнет оборота в 30 млрд долл. благодаря инновационным цифровым технологиям по найму персонала (HR-tech) ${ }^{2}$. Направления применяемых для этого HR-технологий включают в себя решения, связанные с вовлечением сотрудников, диверсификацией ком-

2 URL: https://www.grandviewresearch.com/pressrelease/global-human-resourcemanagement-hrm-market

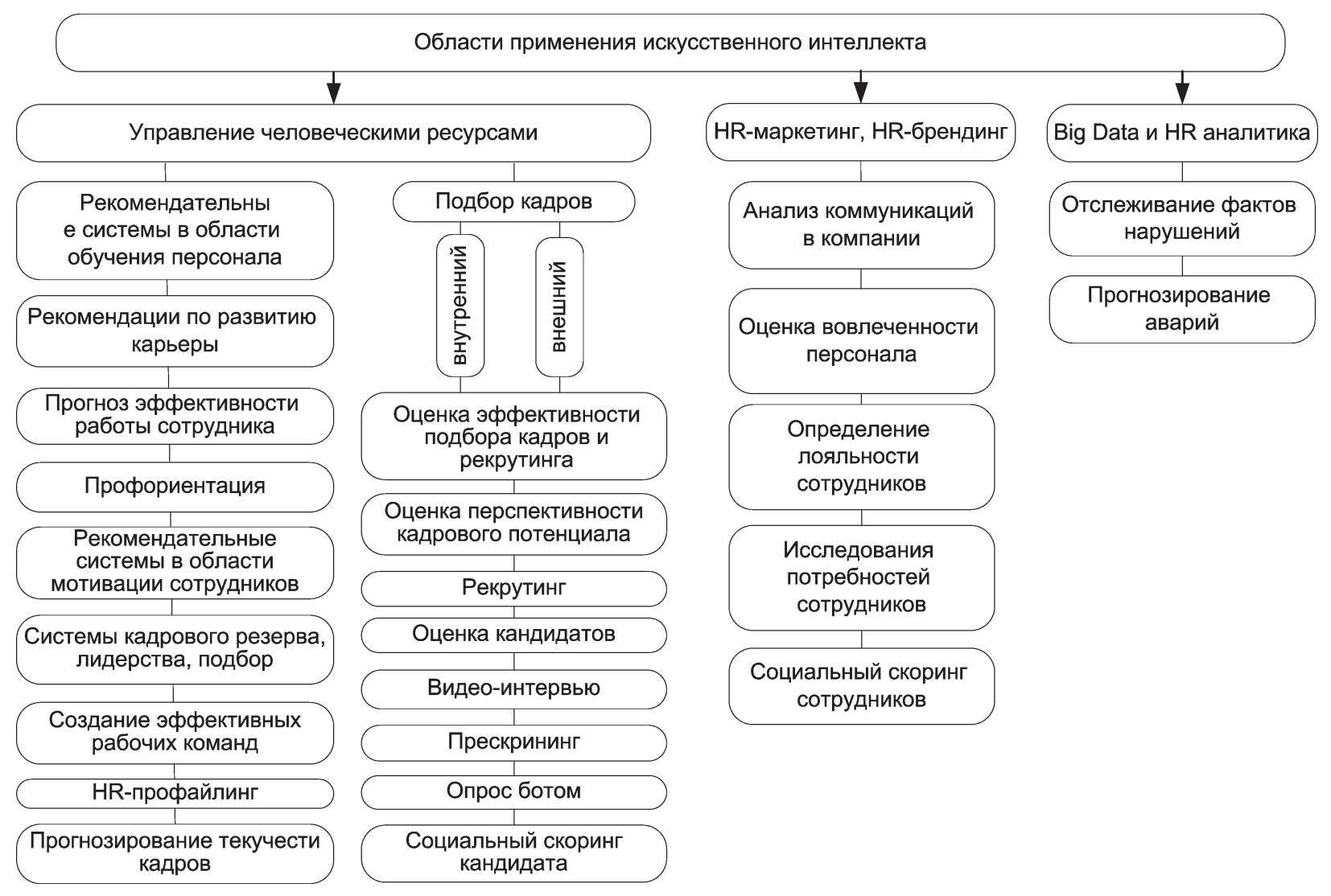

Рис. 1. Области применения искусственного интеллекта в кадровой политике предприятия Источник. Авторская разработка по (Шевелева, Шевелев, 2019; Bersin, 2018; Wislow, 2017). 
паний, расширением корпоративных решений по совершенствованию и эффективному использованию искусственного интеллекта для улучшения работы с персоналом. Большая часть инвестиций на этом рынке будет ориентирована на инструменты для автоматизации рекрутинга, как самой затратной части найма сотрудников.

В качестве современных инструментов искусственного интеллекта для HR-специалистов отечественных предприятий уже доступны сервисы и приложения для автоматизации внутреннего документооборота предприятия, рекрутинга, оценки и аттестации персонала, обучения работников, оценки лояльности и вовлеченности сотрудников, мониторинга HR-бренда, HR-аналитики. К примеру, при поиске кандидатов данные системы способствуют ускорению набора новых людей и экономии времени на долгих собеседованиях. Так, система «Pomato» ${ }^{3}$ проводит анализ информации о кандидатах из их резюме за считанные секунды, а затем разрабатывает индивидуальное техническое интервью. Компания по реализации потребительских товаров «Unilever» использует искусственный интеллект, чтобы проанализировать кандидатов и предсказать их эффективность для компании, при этом на рекрутинге экономит более 50 тыс. часов (Feloni, 2017). Проект «TextRecruit» предлагает автоматизированный интерфейс «Ari», представляющий собой набор чатов в форме бесед с кандидатами. Разработанные в контексте данного проекта чат-боты также позволяют экономить на сотрудниках онлайн-сервисов. Робот «Вера», используемый в российской компании «Пятерочка», сокращает время найма сотрудника до 5,5 дней вместо 7-20 дней до внедрения этой технологии (Маслова, 2018, C. 56). Сервис «Skillaz», являющийся технологией автоматизации подбора кадров и принятия решений, используется компаниями «Азбука вкуса», «Вымпелком», «Leroy Merlen», банком «Открытие» и др. Таким образом, использование искусственного интеллекта при управлении человеческими ресурсами, в частности в вопросах подбора кадров, весьма перспективно.

3 «Рomato», разработка компании «КУSolutions», нацеленная на автоматизацию проверки резюме претендентов в технические фирмы.

\section{Теоретический подход к разработке технологии подбора персонала на основе искусственного интеллекта}

Выбор технологии подбора персонала зависит от многих факторов: профиля вакансии, количества набираемых сотрудников, финансовых возможностей компании и ее корпоративной культуры, состояния рынка труда. На сегодняшний день самой распространенной технологией остается классический рекрутинг. Однако такие факторы современного общества как глобализация, цифровизация, переход бизнеса в онлайн сферу, жесткая конкуренция, большие объемы информации, высокие степени риска при принятии управленческих решений требуют от компании перехода к цифровому рекрутингу состоящего из этапов:

размещение заявки о вакансии в интернет-среде;

осуществление в автоматическом режиме первичного отбора резюме по формальным признакам;

проведение предварительного интервью рекрутинговым чат-ботом;

совершение социального скоринга страниц кандидата в соцсетях;

проведение итоговых собеседований специалистами и линейными руководителями компании;

принятие решения о найме.

Технологическая концепция подбора персонала с применением искусственного интеллекта (технология реализации цифрового рекрутинга) может быть представлена в виде схемы (рис. 2).

Реализация цифрового рекрутинга на базе искусственного интеллекта включает следующие шаги.

1. Открытие вакансии и автоматическое размещение объявления на электронных ресурсах (сайтах поиска работы: Jobs.tut.by, Praca.by, Belmeta.com и др.). HR-специалист составляет объявление о вакансии в системе специализированного HR-портала, созданного на базе технологий искусственного интеллекта. Система осуществляет юридический, семантический, статистический, лексический и грамматический анализ объявления, дает ему оценку на аттрактивность для потенциальных кандидатов и полноту предоставленной информации, по результатам которых про- 
Технологии искусственного интеллекта в управлении человеческими ресурсами

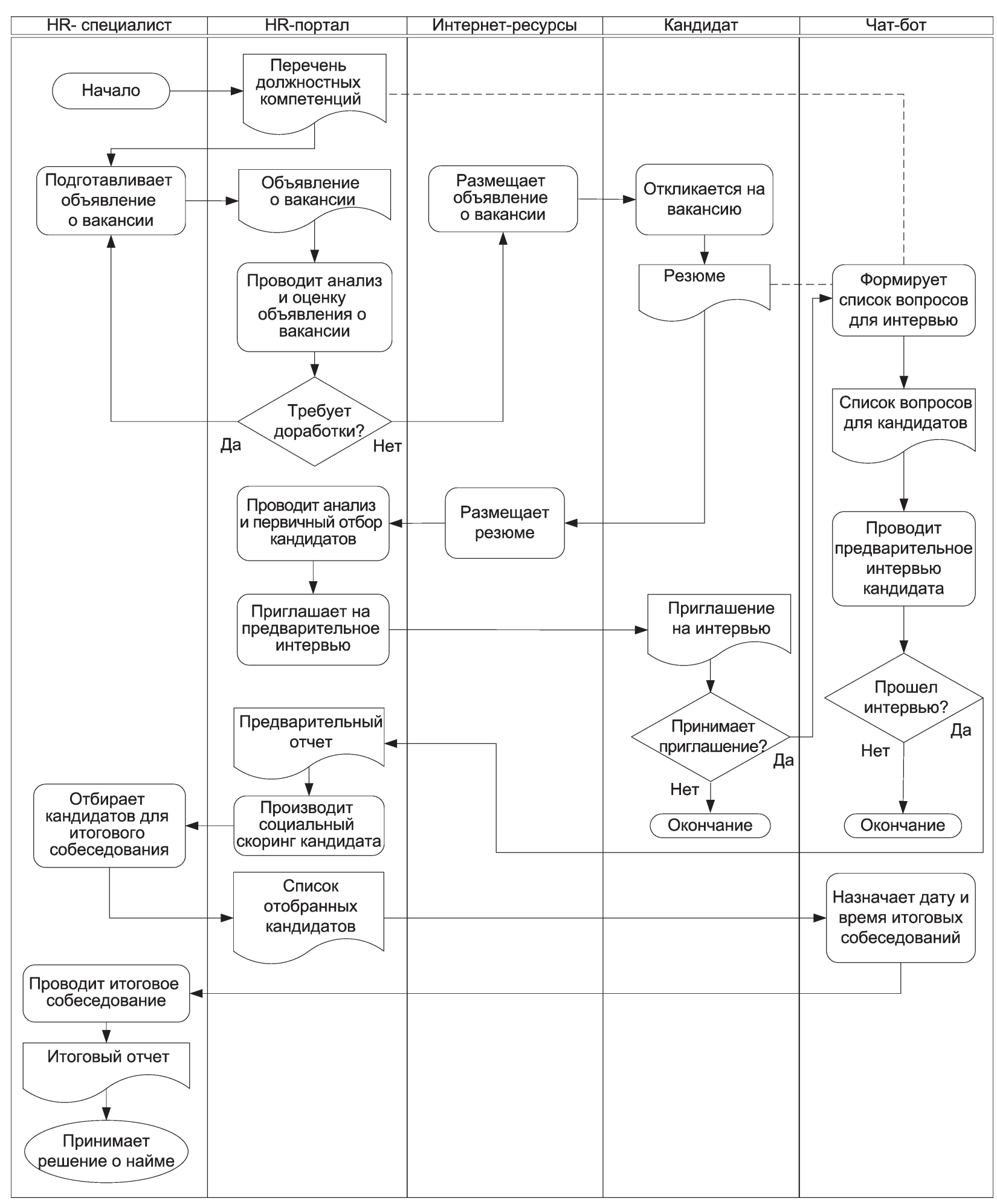

Рис. 2. Технологическая концепция подбора персонала с применением искусственного интеллекта

Источник. Авторская разработка.

водится оптимизация подаваемого объявления и размещение его на электронных площадках.

2. Загрузка резюме соискателем должности на сайт поиска работы, автоматически пересылаемого работодателю.
3. Автоматизированный анализ интеллектуальной системой HR-портала поданных резюме и проведение первичного отбора кандидатов по формальным признакам квалификации (образовательно-квалификационный уровень, последипломное образование, 
опыт работы, знание языков, владение информационными технологиями).

4. Рассылка системой HR-портала приглашения кандидатам на предварительное интервью, проводимое специализированным чат-ботом.

5. Формирование списка вопросов и проведение предварительного интервью с кандидатами. В основе списка вопросов, формируемых чат-ботом для собеседования с кандидатом на должность, лежит перечень должностных компетенций, сформированных по типовой должностной инструкции данной вакансии (который, в свою очередь, разрабатывается на основе Единого тарифно-квалификационного справочника работ и профессий рабочих (ЕТКС) и Единого квалификационного справочника должностей служащих (ЕКСД). Чат-бот отбирает резюме кандидата на должность и проводит предварительное интервью с соискателем, которое состоит из вопросов, определяющих IQ кандидата, его психоэмоциональное состояние и профессиональные навыки. В ходе интервью чат-бот анализирует получаемые ответы и, при необходимости, задает уточняющие вопросы.

6. Анализ собранной информации и формирование предварительного отчета. По окончании интервью бот проводит анализ ответов кандидата и собранной информации методами профайлинга, по результатам которого определяет уровень компетентности, соответствие требованиями вакансии, а также формирует предварительный отчет по каждому претенденту и сводную таблицу по всем кандидатурам.

7. Проведение социального скоринга при наличии у кандидата на должность аккаунтов в социальных сетях и внесение в отчет и сводную таблицу собранной информации.

8. Отбор HR-специалистом кандидатур для итоговых собеседований и составление их расписания. Система HR-портала пересылает специалисту отчеты по отобранным кандидатурам в ходе предварительных мероприятий. Эксперт просматривает предоставленные документы и формирует списки кандидатур для итоговых собеседований. Встроенный в систему чат-бот связывается с кандидатами и назначает дату и время итоговых собеседований, согласуя расписа- ния интервьюирующих специалистов компании и кандидата.

9. Проведение специалистами компании итоговых собеседований и занесение полученных результатов в сводную таблицу подбора кадров.

10. Формирование итоговых отчетов по претендентам на должность, прошедших собеседования и принятие решения о найме.

B результате внедрения HR-портала специалисту по подбору кадров поручается только профессиональная часть работы (столбец «HR-специалист» рис. 2), а система автоматизирует шаблонные действия (столбец «HR-портал» и «Чат-бот» рис. 2).

Многими европейскими организациями при подборе и оценке кадров помимо классических способов (рекрутинг, эксклюзивный поиск, стажировка и обучение молодых кадров (прелиминаринг), поиск и переманивание высококвалифицированных специалистов (хедхантинг); собеседование, тестирование и т. д.) все чаще применяются современные методы, использующие возможности искусственного интеллекта и позволяющие экономить человеческие, временнъе и финансовые ресурсы. Среди таких методов выделяется социальный скоринг - вид скоринга, способный оценить кандидата на должность по социальным характеристикам и спрогнозировать его поведение с помощью анализа присутствия в социальных сетях. Скоринг интернет-ресурсов позволяет проверить информацию в резюме кандидата на достоверность, получить общие психологические характеристики личности соискателя, просчитать риски.

Среди достоинств данного метода оценки кандидата можно выделить:

естественный характер представления информации,

минимальные временные затраты для анализа кандидатуры,

экономичность, т. е. отсутствие дополнительных затрат на приобретение компанией специальных тестовых заданий.

При проведении социального скоринга используется технология оперативной психодиагностики, дающая возможность по визуальной и текстовой информации о человеке выявлять особенности его профориентации, мотивации, управления и ка- 
рьерного роста (кадровый профайлинг), позволяющая:

оценить степень готовности соискателя выполнять круг профессиональных обязанностей должности, на которую он претендует;

дать оценку соответствия действующего сотрудника занимаемой должности;

эффективно формировать кадровый резерв с последующим назначением на вышестоящие должности (по определению особенностей характера претендента на должность, ведущего психотипа с базовой эмоцией, метапрограммного профиля, фокусов языка, архетипа).
В настоящее время для кадрового профайлинга наиболее перспективными считаются его цифровые технологии - электронные решения, помогающие считывать информацию с человека или его социальной страницы (контента) и анализирующие эмоции, личностные качества, характер и темперамент.

Особую известность в кадровом консалтинге и психодиагностике персонала приобрели программные продукты на основе методик: «LAB-profile», «Search Inform Profile Center» и «CEB SHL». В табл. 1 приведено сравнение классических методов подбора кандидатов на должность

Таблица 1

Сравнительный анализ классических методов психодиагностики кандидатов на должность с современными методиками, созданными на базе компьютерных технологий

\begin{tabular}{|c|c|c|c|c|c|c|}
\hline \multirow[b]{2}{*}{ Параметры } & \multicolumn{6}{|c|}{ Классические методы диагностики } \\
\hline & Объективные тесты & $\begin{array}{l}\text { Стандарти- } \\
\text { зованные } \\
\text { самоотчеты }\end{array}$ & $\begin{array}{c}\text { Проективные } \\
\text { методики }\end{array}$ & $\begin{array}{c}\text { Аппаратурные } \\
\text { методики }\end{array}$ & $\begin{array}{c}\text { Диалогические } \\
\text { методики }\end{array}$ & $\begin{array}{l}\text { Патопсихо- } \\
\text { логические } \\
\text { методы }\end{array}$ \\
\hline Сущность & $\begin{array}{l}\text { Тесты, при } \\
\text { выполнении } \\
\text { которых } \\
\text { испытуемый } \\
\text { должен решать } \\
\text { логические, } \\
\text { математические, } \\
\text { пространственные } \\
\text { задачи }\end{array}$ & $\begin{array}{l}\text { Задания в } \\
\text { виде } \\
\text { вопросов или } \\
\text { утверждений, } \\
\text { в которых } \\
\text { испытуемый } \\
\text { сообщает о } \\
\text { себе в форме } \\
\text { ответов }\end{array}$ & $\begin{array}{l}\text { Техники экспе- } \\
\text { риментально- } \\
\text { клинического } \\
\text { исследования } \\
\text { личностных } \\
\text { особенностей }\end{array}$ & $\begin{array}{l}\text { Методы } \\
\text { измерения } \\
\text { психических } \\
\text { процессов с } \\
\text { помощью } \\
\text { специальных } \\
\text { устройств }\end{array}$ & $\begin{array}{l}\text { Общение } \\
\text { интервьюента } \\
\text { и интервьюера } \\
\text { (собеседования, } \\
\text { устные опросы, } \\
\text { интервью) }\end{array}$ & $\begin{array}{l}\text { Искусственное } \\
\text { создание } \\
\text { условий, } \\
\text { выявляющих те } \\
\text { или иные } \\
\text { особенности } \\
\text { психической } \\
\text { деятельности } \\
\text { кандидата }\end{array}$ \\
\hline Достоинства & \multicolumn{6}{|c|}{$\begin{array}{l}\text { Удобны в использовании. } \\
\text { Опросники легко компьютеризировать. } \\
\text { Позволяют оценивать психологические качества испытуемых с максимальной точностью }\end{array}$} \\
\hline Недостатки & \multicolumn{6}{|c|}{$\begin{array}{l}\text { Обработка результатов требует специальной подготовки специалиста. } \\
\text { Узконаправленное исследование. } \\
\text { Если результат находится в пределах средних значений, возникают проблемы с содержательной } \\
\text { интерпретацией. } \\
\text { Обработка результатов требует значительных временных затрат. } \\
\text { Низкая валидность из-за известности методик. } \\
\text { Получение «желательных» ответов, ответов - «угадаек», искаженной информации. } \\
\text { Низкая степень корреляции теоретических заданий с практической деятельностью }\end{array}$} \\
\hline \multirow{2}{*}{ Параметры } & \multicolumn{6}{|c|}{ Методики на базе компьютерных технологий } \\
\hline & LAB-profile & \multicolumn{3}{|c|}{ Search Inform Profile Center } & \multicolumn{2}{|c|}{ CEB SHL } \\
\hline Сущность & \begin{tabular}{|l|} 
Техника \\
установления связи \\
между языковыми \\
и поведенческими \\
проявлениями \\
\end{tabular} & \multicolumn{3}{|c|}{$\begin{array}{l}\text { Программа по выявлению мошеннических } \\
\text { действий, прогнозированию деструктивного } \\
\text { поведения в отношении организации }\end{array}$} & \multicolumn{2}{|c|}{$\begin{array}{l}\text { Психометрические тесты и тесты } \\
\text { на способности, проводимые в } \\
\text { электронном виде }\end{array}$} \\
\hline Достоинства & \multicolumn{6}{|c|}{$\begin{array}{l}\text { Дают достоверную оценку без личных пристрастий и вкусов. } \\
\text { Сокращают сроки и стоимость закрытия вакансий. } \\
\text { Проводят анализ вербальной и невербальной информации. } \\
\text { Осуществляют анализ устойчивых характеристик человека. } \\
\text { Позволяют расширить воронку подбора кандидатов. } \\
\text { Повышают качество кандидатов и снижают текучесть кадров. } \\
\text { Все этапы подбора прозрачны. } \\
\text { Осуществляется hr-специалистом без специальной подготовки } \\
\end{array}$} \\
\hline Недостатки & \multicolumn{6}{|c|}{$\begin{array}{l}\text { Нет четкого описания метапрограммных локусов при их критериальной неопределенности. } \\
\text { Ориентация на оценку стратегии поведения сотрудников (соискателей должности), без учета } \\
\text { индивидуальных ценностных ориентаций и личностных качеств }\end{array}$} \\
\hline
\end{tabular}

Источник. Авторская разработка. 
с методиками, созданными на базе компьютерных технологий.

Обобщение информации о программных продуктах на основе современных методик подбора и оценки кадров позволяет описать технологию применения искусственного интеллекта при сборе информации о кандидате на должность через его аккаунты в социальных сетях (рис. 3).

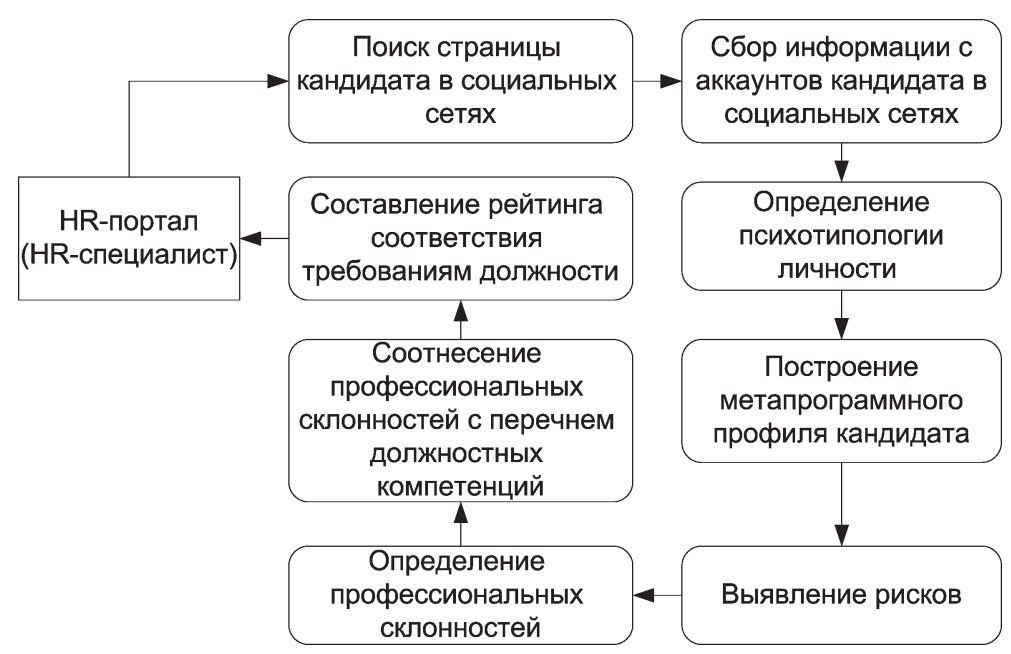

Рис. 3. Технология применения искусственного интеллекта при сборе информации о кандидате с аккаунтов социальных сетей

Источник. Авторская разработка.

При реализации технологии предлагается применять метапрограммы, разработанные на базе теории Н. Хомского, поскольку данное направление является прогрессивным течением психологического анализа личности человека, проводимого в социальных сетях. Метапрограммы - это базовые фильтры восприятия человека и фокусирования его внимания, которые применяются ко всему спектру опыта и определяют образ мышления, актуальные ценностные ориентации, личностные качества, стереотипное поведение, привычки, принципы и образ жизни (Филатов, 2017, С. 13).

Перечень метапрограмм:

мотивации (мотивация ОТ, мотивация К);

«Стиль реагирования» (активность, рефлексия);

референции (внешняя референция, внутренняя референция);

«Поиск и использование информации» (возможности, процедуры);
«Уровень общения и конкретизации информации» (общее, детали);

«Стиль восприятия» (ассоциация, диссоциация);

«Локус сравнения» (сходство, различие, сходство с различием);

«Локус внимания» (сам, другой, система).

Согласно технологии применения искусственного интеллекта, при сборе информации о кандидате с аккаунтов социальных сетей (см. рис. 2) разрабатывается программный продукт «HR Analytics», позволяющий автоматизировать процесс сбора, анализа информации из аккаунтов в социальных сетях кандидата с дальнейшим формированием отчета о его соответствии должности (рис. 4).

Программа «HR Analytics» включает пять программных модулей.

Поисковый модуль (Social Media Search) осуществляет поиск страниц кандидата в социальных сетях с помощью таких программных продуктов как: «Find Face» (поиск аккаунтов через фотографию пользователя), «Pipl» (поиск страниц по номеру телефона, электронной почте,

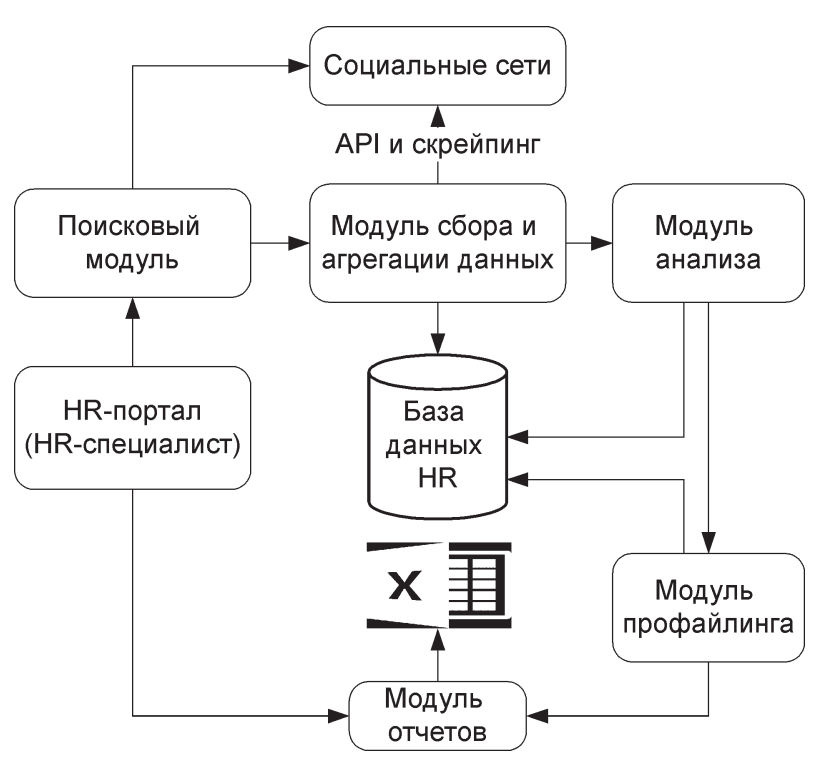

Рис. 4. Архитектура программного продукта «HR Analytics»

Источник. Авторская разработка. 
имени пользователя), «Login.stop-list.info» (поиск аккаунта по никнейму).

Модуль сбора и агрегации данных (Social Media Collecting) извлекает информацию из обнаруженных страниц кандидата в социальных сетях. Данный блок представляет собой самостоятельный программный продукт, разработанный на языке «Рython», получающий из заданного профиля социальной сети данные пользователя (рис. 4). Сбор данных осуществляется с использованием публичных API социальных сетей и подходов скрейпинга информации с помощью фрэймворка «Scrapy». Собранные сведения поступают и сохраняются в базе данных «Mongo DB». Анализ работ исследователей, занимающихся установлением соответствия информации из аккаунтов в социальных сетях с психологическими характеристиками их владельцев (Cristani, 2013; Liu, Preotiuc-Pietro, Samani, Moghaddam, Ungar, 2016; Chandra, Lin,
Carpenter, Keong, Lyle, Preoюiuc-Pietro, 2017; Латышев, Талалаев, Фраленко, Хачумов, Хачумов, 2019; Филатов, 2017), позволяет составить алгоритм сбора и обработки пользовательских данных (рис. 5).

Модуль анализа (Social Media Analysis) анализирует собранную информацию и соотносит ее по формальным признакам с метапрограммами личности. Данный модуль реализован на языке «Python» с использованием специализированных библиотек для машинного обучения таких, как Tensorflow, Keras, Scikit-learn, Gensim.

Анализ профиля кандидата целесообразно проводить с помощью методов многоклассовой классификации на основании сверточных нейросетей. Особенностью данного вида классификации является то, что его можно использовать как для обработки текста, так и для анализа фотографий, размещенных в профилях пользователей, что позволяет унифицировать методику сбора

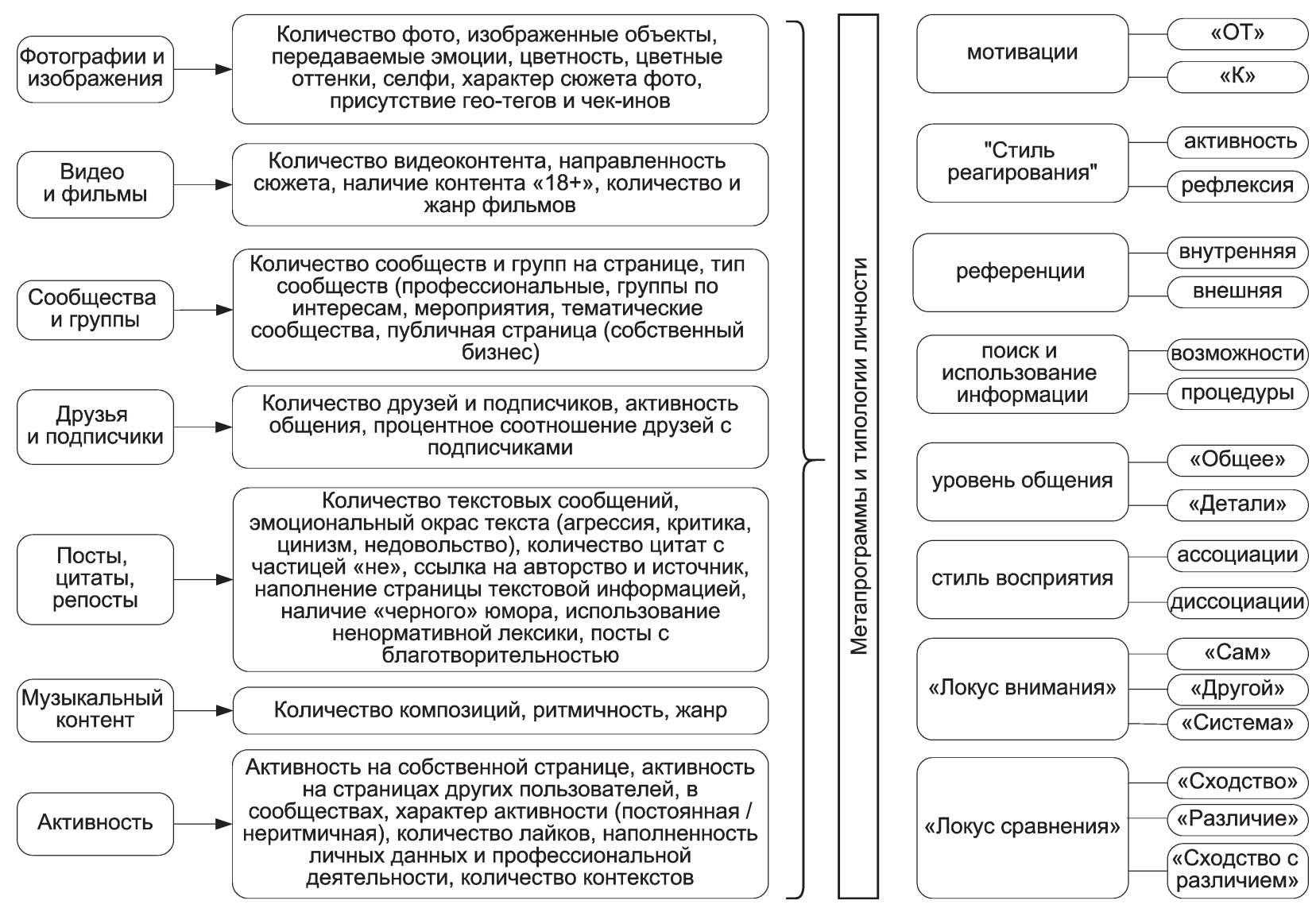

Рис. 5. Алгоритм сбора и обработки нейронной сетью пользовательских данных из социальных сетей

Источник. Авторская разработка по (Cristani, 2013; Liu, 2016; Chandra, 2017; Латышев, Талалаев, Фраленко, Хачумов, Хачумов, 2019; Филатов, 2017). 
и подготовки данных, обучения и оценки метрики качества модели классификаторов.

Задача многоклассовой классификации может быть формально описана следующим образом:

$$
\begin{aligned}
& \text { Исходные данные } \\
& \left\{x_{1}, \ldots, x_{l}\right\} \subset X-\text { выборка; } \\
& y_{i}=y\left(x_{i}\right) \in\{1, \ldots, K\}, i=1, \ldots, l-\text { известные }
\end{aligned}
$$
ответы.

\section{Найти}

$\boldsymbol{a}: \boldsymbol{X} \rightarrow \boldsymbol{Y}$ - алгоритм, решающий функцию, приближающую $Y$ на всем множестве объектов $X$.

Поскольку решение задачи многоклассовой классификации трудоемко и определение оценки качества полученной модели затруднительно, на данном этапе правомерно свести задачу к построению более простых в решении и точных в оценке бинарных классификаторов.

Для того, чтобы свести задачу многоклассовой классификации к бинарной, было рассмотрено $K$ задач бинарной классификации, где каждый класс изображения отделяется от всего набора остальных классов (по принципу «каждый против всех»). При таком решении обучающей выборкой для для каждого класса будет являться вся выборка $X$.

Для каждого класса $\in\{1, \ldots, K\}$ множество ответов $z$, где $z_{j}=y_{j}$ если $y_{j}=k$, иначе $z_{j}=0$.

Решением данной задачи будет являться классификатор $b_{k}(x)$, определяющий вероятность принадлежности к классу $k$.

В качестве окончательного класса для заданного изображения выбирается класс, вероятность которого максимальна среди всех полученных значений: $a(x)=\arg \max b_{k}$, где $k=1, \ldots, K$.

На рис. 6 приведена обобщенная архитектура нейронной сети для классификации изображений.

Для оценки качества модели такого классификатора зачастую используется метрика AUC-ROC (AUC «Area Under the Curve» - площадь под кривой ошибок; ROC «Receiver Operating Characteristic» - кривая ошибок), которая позволяет наиболее точно оценить модель и, соответственно, более качественно обучить ее на имеющейся выборке данных. Предлагаемая метрика определяется тем фактом, что чем больший TPR (True Positive Rate - количество носителей признака, верно классифицированных, как несущие признак) возможно получить при меньшем FPR (False Positive Rate - количество объектов, не несущих признак, ошибочно классифицированных, как несущие признак), тем лучше качество классификатора. Вычисляется данная метрика, как площадь под кривой ошибок $\mathrm{ROC}$ :

$$
\boldsymbol{A U C}=\int_{0}^{1} f(x) d x,
$$

где $\boldsymbol{f}(\boldsymbol{x})=\boldsymbol{T P R}, \boldsymbol{x}=\boldsymbol{F P R}$.

Качество получаемой модели тем выше, чем больше значение AUC (рис. 7).

Данный подход для классификации также эффективен при эмоциональном анализе текстов. В этом случае несколько изменяется структура и последовательность слоев сверточной нейросети, а на вход вместо изображения подается векторное представление слов текста («Word Embeddings»). Использование сверточной нейронной сети

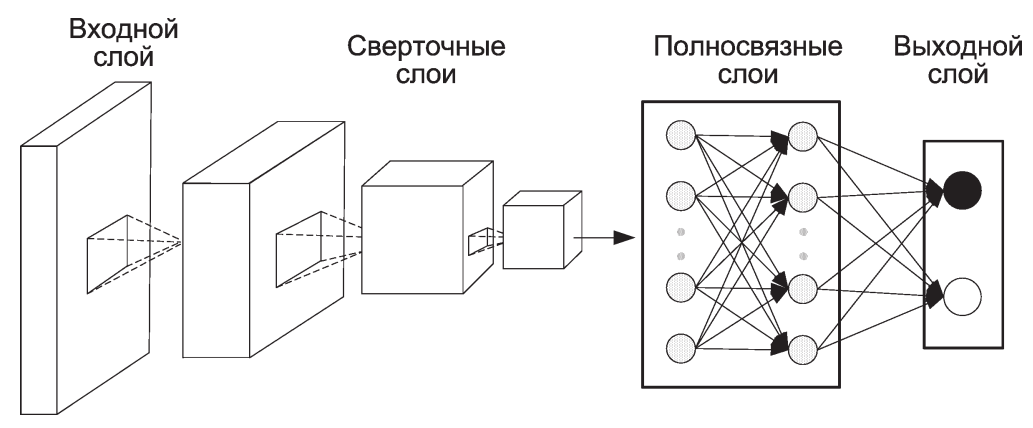

Рис. 6. Обобщенная архитектура нейронной сети для бинарной классификации изображений

Источник. Авторская разработка. 


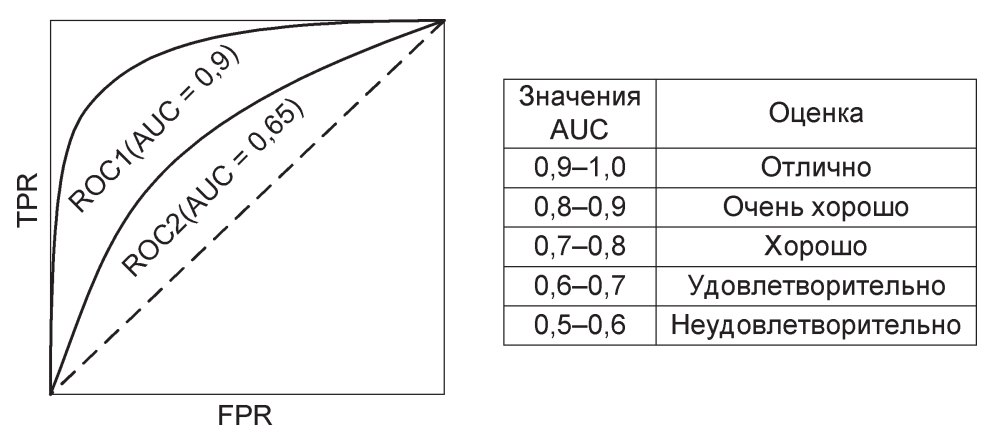

Рис. 7. Зависимость качества модели бинарного классификатора от значений AUC

Источник. Авторская разработка.

позволяет классификатору учитывать в совокупности контекст и содержимое текста, а не классифицировать его на основании отдельного набора слов, что повышает качество классификации.

Для обучения нейронных сетей в модуле анализа предлагается использовать публичные наборы данных RusTweetCorp, ImageNet и др., применяемые для классификации изображений и текста.

Модуль профайлинга (Human Resources Profiling) сначала создает список деловых качеств и личностных характеристик кандидата по метапрограммам личности, а затем заносит его в базу данных. При этом формируется рейтинг соответствия кандидата требованиям должности, включающий:

определение психотипологии личности (выявление сильных, умеренных и слабых метапрограммных профилей кандидата);

построение метапрограммного профиля с использованием метрик (тенденции образа жизни; преобладающие способности; жизненные ценности; склонность к расизму и экстремизму; конфликтность в общении; стереотипы мышления; личностные качества; склонности к риску; проявления депрессивного состояния; уровень лояльности; отрицательные черты характера; положительные черты характера; факторы адаптации в профессиональной деятельности; соответствие корпоративной культуре; профессиональные склонности) (Филатов, 2017);

выявление рисков (зависимое поведение от алкоголя, азартных и компьютерных игр; связь с лицами, ведущими асоциальный образ жизни; склонность к правонарушениям); определение профессиональных склонностей;

соотнесение выявленных профессиональных склонностей с должностью, на которую претендует кандидат.

Программный модуль профайлинга реализуется на языке «Рython» с использованием библиотек Pandas, NumPy, Scikit-learn, PyMongo.

Модуль отчетов (Human Resources Reporting) представляет собой веб-приложение, реализованное с использованием JavaScript-библиотеки «React», формирующее итоговый отчет о соответствии качеств кандидата требованиям должности. При этом, программное приложение позволяет экспортировать отчет в формате Excel для удобства дальнейшей работы HR-специалиста с полученными сведениями.

\section{Использование результатов подбора персонала на основе технологии искусственного интеллекта в практике}

Участниками процесса внедрения современных технологий на базе искусственного интеллекта в области управления человеческими ресурсами будут выступать:

собственники предприятий и наниматели;

кадровые службы предприятия и HR-специалисты;

IT-компании и специалисты;

органы служб занятости;

профсоюзные организации;

представители государственных и местных органов власти.

Роль и задачи участников данного процесса представлены в табл. 2.

Таким образом, основная задача внедрения искусственного интеллекта в управление трудовыми ресурсами - повышение производительности и конкурентоспособности предприятий с минимизацией социально-экономических и психологических рисков для его работников ${ }^{4}$.

На примере аккаунта магистранта факультета экономики и бизнес-управления УО «Витебский государственный технологический университет» рассмотрим прак-

4 Ванкевич Е.В. 2011. Кадровые службы: направления активизации. Беларуская думка. № 1. С. 52 
Участники процесса внедрения технологий подбора человеческих ресурсов на базе искусственного интеллекта отечественными предприятиями, их роль и основные задачи

\begin{tabular}{|c|c|c|}
\hline Участники процесса & Приоритетные цели & Основные задачи \\
\hline $\begin{array}{l}\text { Представители } \\
\text { государственных и } \\
\text { местных органов } \\
\text { власти. } \\
\text { Органы служб } \\
\text { занятости }\end{array}$ & $\begin{array}{l}\text { Устойчивое социально- } \\
\text { экономическое развитие } \\
\text { страны (региона) }\end{array}$ & $\begin{array}{l}\text { Создание благоприятных правовых условий для } \\
\text { внедрения и применения программных продуктов на } \\
\text { базе искусственного интеллекта белорусскими } \\
\text { предприятиями. } \\
\text { Предупреждение роста безработицы и снижения уровня } \\
\text { жизни в результате внедрения новых технологий и } \\
\text { сокращения ручной работы. } \\
\text { Обеспечение социальных гарантий высвобождаемым } \\
\text { работникам }\end{array}$ \\
\hline $\begin{array}{l}\text { Собственники } \\
\text { предприятий и } \\
\text { наниматели }\end{array}$ & $\begin{array}{l}\text { Повышение } \\
\text { конкурентоспособности, } \\
\text { инвестиционной } \\
\text { привлекательности, } \\
\text { имиджа предприятия }\end{array}$ & $\begin{array}{l}\text { Внедрение новых технологий, позволяющих } \\
\text { разрабатывать и осуществлять конкурентные стратегии } \\
\text { предприятия. } \\
\text { Рост прибыли за счет максимальной загрузки ресурсов } \\
\text { предприятия. } \\
\text { Формирование условий для эффективной } \\
\text { инвестиционной деятельности }\end{array}$ \\
\hline $\begin{array}{l}\text { Профсоюзные } \\
\text { организации }\end{array}$ & $\begin{array}{l}\text { Защита прав работников } \\
\text { предприятия }\end{array}$ & $\begin{array}{l}\text { Участие в подготовке нормативной документации. } \\
\text { Недопущение необоснованных увольнений работников и } \\
\text { снижения их доходов }\end{array}$ \\
\hline $\begin{array}{l}\text { Кадровые службы } \\
\text { предприятия, } \\
\text { HR-специалисты }\end{array}$ & $\begin{array}{l}\text { Освоение современных } \\
\text { технологий кадровой } \\
\text { работы; } \\
\text { Формирование трудового } \\
\text { потенциала предприятия, } \\
\text { кадровое планирование }\end{array}$ & $\begin{array}{l}\text { Внедрение в кадровую политику предприятия } \\
\text { современных инструментов на базе искусственного } \\
\text { интеллекта. } \\
\text { Осуществление реструктуризации предприятий с } \\
\text { минимальными рисками для работников. } \\
\text { Сотрудничество с органами государственной и местной } \\
\text { власти, органами служб занятости, профсоюзами }\end{array}$ \\
\hline $\begin{array}{l}\text { IT-компании и } \\
\text { специалисты }\end{array}$ & $\begin{array}{l}\text { Разработка, внедрение и } \\
\text { сопровождение } \\
\text { программных продуктов } \\
\text { на базе искусственного } \\
\text { интеллекта }\end{array}$ & $\begin{array}{l}\text { Разработка программных продуктов на базе } \\
\text { искусственного интеллекта по запросам белорусских } \\
\text { предприятий. } \\
\text { Обучение работе с программами на базе искусственного } \\
\text { интеллекта HR-специалистов и работников кадровых } \\
\text { служб }\end{array}$ \\
\hline
\end{tabular}

Источник. Авторская разработка.

тическую применимость технологии использования искусственного интеллекта при социальном скоринге.

Этап 1. Сбор информации с аккаунта социальной сети.

В аккаунте приведена полная личная информация. Пользователь «неритмично» ведет страницу, меняет аватары со своим изображением. В музыке предпочтения отданы современным ритмичным композициям. На фото изображены спокойные места, домашние животные. Преобладают одиночные фотографии самого пользователя в домашней обстановке, практически отсутствуют фото вне дома. При этом превалируют яркие цвета. Помимо фотографий есть изображения известных артистов и героев иностранных мультипликационных фильмов. На странице приведено минимальное количество фото, постов, событий, прослеживается 3-4 контекста. Отсутствует политический и контент с вредными привычками. При членстве в группах отдано предпочтение юмористической направленности, здоровому образу жизни, саморазвитию, музыке, дизайну; присутствуют сообщества «18+». Видео представлено направлениями: комедии, животные, дети, кулинария, музыкальные клипы, макияж. Лингвистическая структура постов и ответов - активная.

Страница имеет следующую статистику: 16 фото, 65 друзей, 206 подписчиков, 96 сообществ, 190 видео, 107 подарков.

Этап 2. Определение психотипологии личности.

Анализ собранной информации позволил выявить значительно выраженные метапрограммные полюса («Мотивация К», «Сходство», «Рефлексия»), программные полюса, проявленные в средней степени 
(«Сам», «Детали», «Процедуры») и метапрограммы без четко выраженного паттерна («Референции», «Стиль восприятия»).

Этап 3. Построение метапрограммного профиля.

Метапрограммный профиль пользователя представлен на рис. 8.

Согласно построенного профиля, у пользователя выявлены следующие личностные качества: аккуратный, вежливый, дружелюбный, культурный, работоспособный, застенчивый, интеллигентный, интеллектуальный, отзывчивый, прагматичный, стабильный, брезгливый, исследующий, прозорливый, точный, остроумный, мстительный, меркантильный, работоспособный, консервативный, преданный.

В ходе анализа страницы пользователя, признаков депрессивного состояния, склонности к расизму и экстремизму не обнаружено. Соотносимость с корпоративной культурой по признакам «вредные привычки», «контент «18+», «нецензурная брань», «жаргонная речь» и т. д. -8 из 10 баллов (шкала рейтинга: 1 - явно выраженные признаки, 10 - отсутствие признаков).

По собранной информации со страницы пользователя можно сделать вывод о том, что человек направлен на результат, у него прослеживается невысокая склонность к риску, относительная слабость мотивации к внешним воздействиям, неблагоприятным условиям, отсутствие желания «глубокого контакта» с людьми. Процесс принятия его решений основывается на отработанных в прошлом алгоритмах анализа и оценки ситуации. Память основана на последовательном запоминании материала,

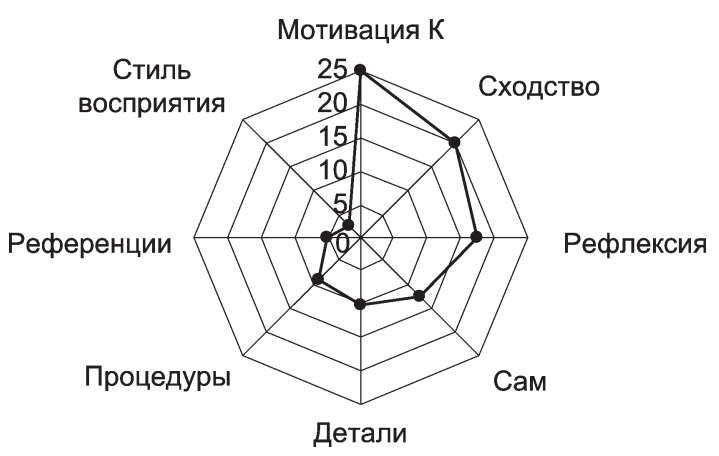

Рис. 8. Метапрограммный профиль пользователя Источник. Авторская разработка. составлении схем и алгоритмов, разделении запоминаемого материала на части. Такой сотрудник мотивирован необходимостью. Человек настроен не на поиск нового опыта, творчество и создание нового продукта, а на его модернизацию и улучшение. В конфликте он готов отстаивать собственное видение и план реализации имеющейся цели. Ценности его традиционны, больше связаны с безопасностью, сбережением, организацией, контролем и дисциплинированностью.

Этап 4. Выявление рисков.

Вероятность проявления рисков определялась в виде балльной оценки по шкале от 1 до 10. Максимальное количество баллов интерпретировалось с отсутствием риска, 1 балл - с явным наличием фактора риска. Результаты: зависимое поведение от алкоголя - 10 баллов, зависимость от азартных и компьютерных игр - 10 баллов; связь с лицами, ведущими асоциальный образ жизни - 9 баллов; склонность к правонарушениям - 10 баллов. Таким образом, количество набранных рейтинговых баллов составило 39.

Этап 5. Определение профессиональных склонностей.

В качестве профессиональных склонностей рекомендованы: менеджер среднего звена, IT-специалист, налоговый инспектор, мастер по настройке оборудования, экономический аналитик, статист, преподаватель, научный сотрудник, экономист.

Этап 6. Соотнесение выявленных профессиональных склонностей с должностью.

Анализ рассмотренного в качестве примера аккаунта магистранта факультета экономики и бизнес-управления в соцсети, выявил адекватность способностей квалификации «Экономист».

Направления дальнейшего исследования включают разработку итогового рейтинга кадрового профайлинга, заключающегося в определении совокупного балла кандидата на должность в результате его оценки по ряду критериев, имеющих различные удельные веса и агрегированных в интегральный показатель - совокупный профайлинговый балл. Согласно разработанной технологической концепции подбора персонала с применением искусственного интеллекта (рис. 2) в качестве критериев выб- 
раны результаты: анализа резюме кандидата, предварительного интервью, социального скоринга и итоговых собеседований.

Использование искусственного интеллекта при управлении человеческими ресурсами является неотъемлемой частью процесса цифровизации экономики. Благодаря уникальным возможностям искусственного интеллекта появляются новые подходы в поиске, подборе, обучении, мотивации и оценке эффективности трудовых ресурсов. Одно из прогрессивных направлений найма сотрудников - социальный скоринг, основанный на использовании технологии Big Data и базирующийся на цифровых инструментах кадрового профайлинга. Данное направление по сравнению с классическим инструментарием подбора кадров позволяет объективно, экономично и быстро проверить достоверность информации в резюме, составить психологический портрет кандидата на основании глубокого анализа и беспристрастной оценки информации профиля из соцсетей, выявить его потенциал и проверить соответствие профессиональных и личностных качеств требованиям должности.

Недостатками данной технологии подбора персонала выступают: ведение «фейковых» страниц, этическая сторона сбора и обработки личной информации, непринципиальные ошибки в составленных характеристиках.

Эти недостатки устранимы в будущем с обновлением законодательной базы относительно сбора и обработки личных данных из социальных сетей, развитием технологий и средств обработки больших массивов данных.

\section{СПИСОК ЛИТЕРАТУРЫ (REFERENCES)}

Ванкевич Е.В., Кастел-Бранко Э. 2017. Информационно-аналитическая система рынка труда и прогнозирования потребности в кадрах: содержание и направления формирования в Республике Беларусь. Белорусский экономический журнал. № 2. С. 73-92. [Vankevich E.V., CastelBranco E. 2017. Labour market information system and skills anticipation (lmis): content and directions of formation in the Republic of Belarus. Belorusskiy ekonomicheskiy zhurnal. No 2. PP. 73-92. (In Russ.)]

Латышев А.В., Талалаев А.А., Фраленко В.П., Хачумов В.М., Хачумов М.В. 2019. Методы оценки личностных факторов по визуальной информации, публикуемой в социальных сетях (обзор). Мир науки. Педагогика и психология. № 1. T. 7. URL: https://mir-nauki.com/PDF/ 27PSMN119.pdf[Latyshev A.V., Talalaev A.A., Fralenko V.P., Khachumov V.M., Khachumov M.V. 2019. The methods for assessing personal factors using visual information that is published on social networks (review). Mir nauki. Pedagogika $i$ psikhologiya. No 1. Vol. 7. URL: https://mirnauki.com/PDF/27PSMN119.pdf (In Russ.)]

Маслова В.М. 2018. Система рекрутинга с элементами искусственного интеллекта. Экономические системы. № 1. С. 56-59. [Maslova V.M. 2018. The recruiting system with elements of artificial intelligence. Ekonomicheskie sistemy. No 1. PP. 56-59. (In Russ.)]

Пантелеева Т.А., Арустамов Э.А., Максаев А.А. 2019. Возможности искусственного интеллекта в управлении кадровыми ресурсами в условиях свободного предпринимательства Отходы и ресурсы. № 3. T. 6. URL: https:// resources.today/PDF/10ECOR319.pdf [Panteleeva T.A., Arustamov E.A., Maksaev A.A. 2019. The possibilities of artificial intelligencein the management of human resources in a free enterprise. Otkhody $i$ resursy. No 3. Vol. 6. URL: https://resources.today/ PDF/10ECOR319.pdf (In Russ.)]

Филатов А.В. 2017. Профайлинг. Как разбираться в людях и прогнозировать их поведение. Москва: Интеллектуальная издательская система Ridero. [Philatov A.B. 2017. Profiling. How to understand people and predict their behavior. Moscow: Intellektual'naya izdatel'skaya sistema Ridero. (In Russ.)]

Шевелева А.В., Шевелев В.С. 2019. Практика применения искусственного интеллекта в сфере управления персоналом нефтегазовых компаний. Вестник Кемеровского государственного университета. Серия: Политические, социологические и экономические науки. Т. 4. № 3. С. 354360. [Sheveleva A.V., Shevelev V.C. 2019. Practical application of artificial intelligence in human resource management of oil and gas companies. Vestnik Kemerovskogo gosudarstvennogo universiteta. Seriya: Politicheskie, sotsiologicheskie i ekonomicheskie nauki. Vol. 4. No 3. PP. 354-360. (In Russ.)]

Bersin J. 2018. AI in HR: A Real Killer App. URL: https://joshbersin.com/ai-in-hr-a-real-killer-app/

Cristani M., Vinciarelli A., Segalin C., Perina A. 2013. Unveiling the multimedia unconscious: Implicit cognitive processes and multimedia content analysis. Proceedings of the 21st ACM international conference on Multimedia. PP. 213-222. 
Chandra S., Lin W., Carpenter J., Keong W., Lyle H., Preoюiuc-Pietro D. 2017. Studying personality through the content of posted and liked images on Twitter. Conference: ACM Web Science. Troy, NY, USA. URL: https://www.sas.upenn.edu/ danielpr/files/persimages17websci.pdf

Feloni R. 2017. Consumer-goods giant Unilever has been hiring employees using brain games and artificial intelligence - and it's a huge success and Beyond. URL: https://www.businessinsider.com/ unilever-artificial-intelligence-hiring-process-6
Liu L., Preotiuc-Pietro D., Samani Z.R., Moghaddam M.E., Ungar L. 2016. Analyzing personality through social media profile picture choice. Proceedings of the Tenth International AAAI Conference on Web and Social Media (ICWSM 2016). PP. 211-220.

Wislow E. 2017. Top 5 ways to use artificial intelligence (AI) in human resources. Big Data. Made Simple. URL: https://bigdata-madesimple.com/5ways-to-use-artificial-intelligence-ai-in-humanresources/

In citation: Belorusskiy Economicheskiy zhurnal. 2020. No 2. PP. 38-51.

Belarusian Economic Journal. 2020. No 2. PP. 38-51.

\title{
ARTIFICIAL INTELLIGENCE TECHNOLOGIES IN HUMAN RESOURCES MANAGEMENT
}

\author{
Alena Vankevich ${ }^{1}$, Iryna Kalinouskaya ${ }^{1}$ \\ Authors affiliation: ${ }^{1}$ Vitebsk State Technological University (Vitebsk, Belarus). \\ Corresponding author: Alena Vankevich (vankevich_ev@tut.by).
}

ABSTRACT. There have been developed methods for using artificial intelligence technologies in an organization's human resources management system based on the processing and interpretation of big data. Substantiated is the concept of using artificial intelligence for social scoring when hiring potential candidates for jobs. In accordance with that concept, a software product architecture has been developed that makes it possible to apply the personnel profiling technologies, based on the information from social media, for assessing the degree of the applicant's readiness to fulfill professional duties of the position he/she is applying for. Suggested are recommendations on the application of directions for the implementation of artificial intelligence.

KEYWORDS: human resources management, personnel selection, artificial intelligence, social scoring, personnel profiling.

JEL-code: J24, M51.

DOI: $10.46782 / 1818-4510-2020-2-38-51$

Received 28.02.2020 